\title{
The Sustainable Island Development Evaluation Model and Its Application Based on the Nonstructural Decision Fuzzy Set
}

\author{
Quanming Wang, ${ }^{1,2}$ Peiying Li, ${ }^{1,3}$ and Qinbang Sun ${ }^{2}$ \\ ${ }^{1}$ College of Environmental Science and Engineering, Ocean University of China, Qingdo 266003, China \\ ${ }^{2}$ National Marine Environment Monitoring Center, Dalian 116023, China \\ ${ }^{3}$ The First Institute of Oceanography, SOA, Qingdao 266061, China
}

Correspondence should be addressed to Quanming Wang; qmwang@nmemc.gov.cn

Received 27 February 2013; Accepted 7 April 2013

Academic Editor: Fuding Xie

Copyright (C) 2013 Quanming Wang et al. This is an open access article distributed under the Creative Commons Attribution License, which permits unrestricted use, distribution, and reproduction in any medium, provided the original work is properly cited.

\begin{abstract}
Due to the complexity and diversity of the issue of sustainable island development, no widely accepted and applicable evaluation system model regarding the issue currently exists. In this paper, we discuss and establish the sustainable development indicator system and the model approach from the perspective of resources, the island environment, the island development status, the island social development, and the island intelligence development. We reference the sustainable development theory and the sustainable development indicator system method concerning land region, combine the character of the sustainable island development, analyze and evaluate the extent of the sustainable island development, orient development, and identify the key and limited factors of sustainable island development capability. This research adopts the entropy method and the nonstructural decision fuzzy set theory model to determine the weight of the evaluating indicators. Changhai County was selected as the subject of the research, which consisted of a quantitative study of its sustainable development status from 2001 to 2008 to identify the key factors influencing its sustainability development, existing problems, and limited factors and to provide basic technical support for ocean development planning and economic development planning.
\end{abstract}

\section{Introduction}

In recent years, the overdevelopment of and random construction on numerous islands has directly influenced the natural environment and the ecological balance of the islands, which has resulted in environmental deterioration and resource reduction and has even had catastrophic effects on the ecological environment of the islands [1]. Therefore, the quantitative description and evaluation of the extent of sustainable island development and the development orientation and restrictive factors are important for formulating island development strategy and developing future island economies [2].

Extensive research on sustainable development has been conducted at home and abroad, and many evaluation index systems and evaluation models related to sustainable development have been established, such as the ecological footprint model (EF) [3, 4], green GDP accounting system [5], resource carrying capacity model [6], and human development index (HDI) model [7]. But so far, because of the complexity and diversity of sustainable island development $[2,8-14]$, no generally accepted and applicable evaluation index system for sustainable island development has been established. This study has referred to the references about basic sustainable development theory [15-18] and the concept of a sustainable development index system $[1,2,19-$ 21], selected indexes from the point of view of the survival resource support, ecological environmental support, economic development support, and social and intellectual support [22], and established the evaluation index system and the evaluation model for sustainable island development. In addition, for multipurpose evaluation and decision, the rationality of the setting weights is emphasis and difficulty of evaluation and decision. The key of multipurpose evaluation and decision all the time is to improve the rationality of weight setting to avoid arbitraries. While analyzing the AHP 


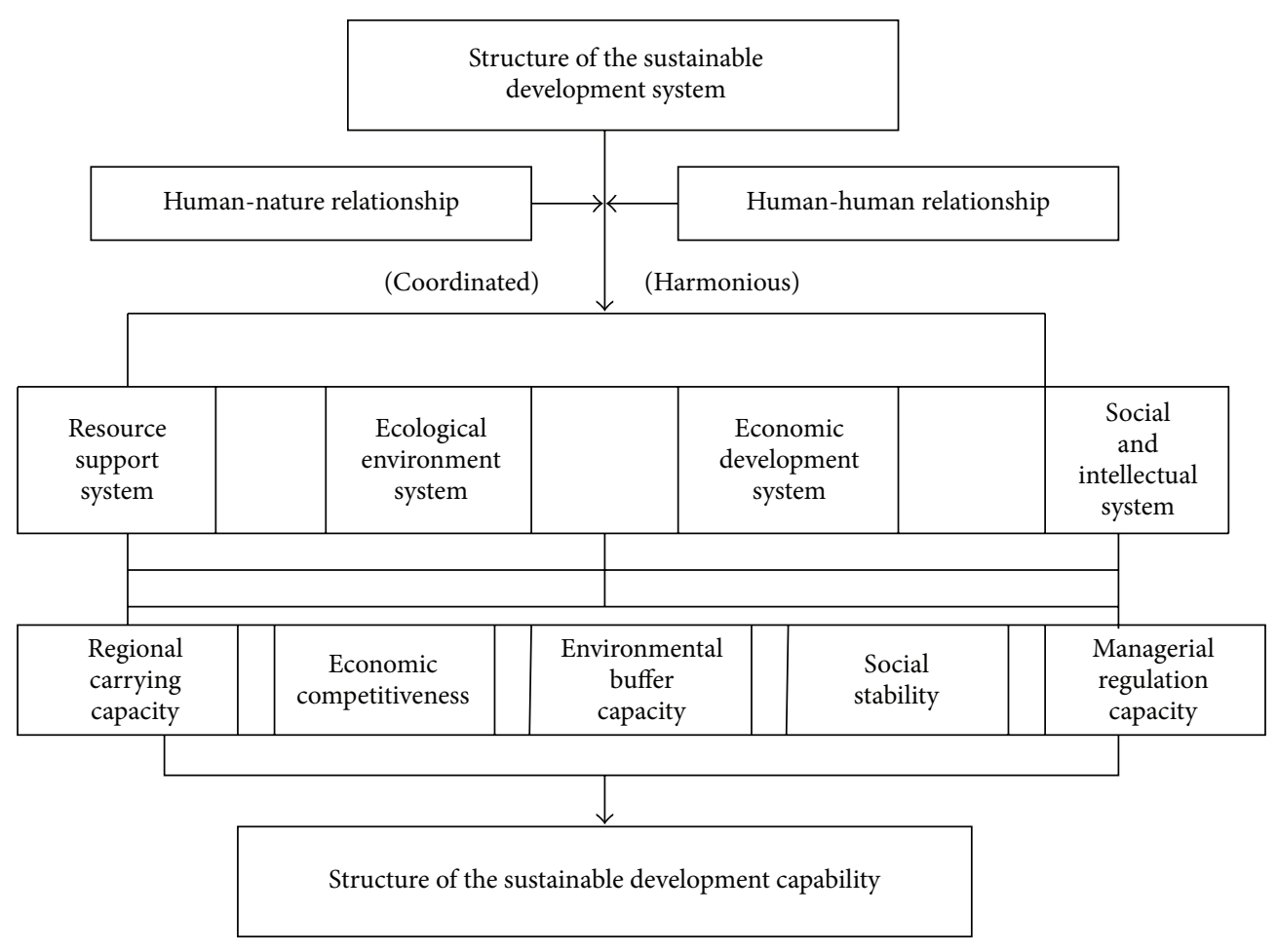

FIGURE 1: The framework of the sustainable development evaluation system.

model, Professor Chen Shouyu [23] made a binary comparison of the properties of elements by comparing their importance. Subsequently, with certain defects, the nonstructural decision-making fuzzy theory model has been offered. The nonstructural decision fuzzy set has been widely used in the evaluation of water resources carrying capacity [24] and the coordinated development of marine resources [25] and provides a scientific and reasonable decision method for the rationality of the subjective weight setting. The synthetic evaluation criterion weight was determined by combining the entropy weight and the nonstructural decision fuzzy set theory model in this paper. This paper analyzed and evaluated the extent of island sustainable development, development orientation, and restrictive factors to provide relevant theoretical support for the reasonable utilization and effective protection of island resources.

\section{Materials and Methods}

\subsection{Sustainable Development Evaluation Model for Islands}

2.1.1. Evaluation Index System Framework. The framework is the brief summary for the evaluation object, and the framework model can be used to define the boundary, composition, and structure of the evaluation object, to describe the correlations and interacting mechanisms of the subsystems, and to help the evaluator select and organize a series of problems [26]. The integration of population, resources, environment, development, and management decision-making is the core of sustainable development strategy and is also the key to coordinating human-nature relationships and interpersonal relationships (Figure 1). The coordination and sustainability of island development is the basic principle and core connotation for island sustainable development [8].

This research evaluated the sustainable island development potential from the view of the survival resource support, ecological environmental support, economic development support, and social and intellectual support. The survival resource support system is the basic condition for sustainable island development; the ecological environment system is the restrictive condition for sustainable island development; the economic development support system is the impetus condition for sustainable island development; the social and intellectual support system is the assuring and continuing condition for island sustainable development [27].

\subsubsection{Evaluation Indexes of Sustainable Island Development.} The index is the measurement of specific attributes of sustainable island development and the subsystems, which is further abstracted from the framework model and is a further decomposition of the overall goal and subgoals of sustainable development. This research has referred to such factors as island survival resources, survival sustainability, island development cost, level of environmental control and protection, level of ecological development, level of social development, educational, science, technology, and management ability. By combining the selection principle of the sustainable development evaluation index with the extent of collecting data about sustainable island development, this paper adopted the principal component analysis method, frequency statistical method, theoretical analysis method, and the Delphi method to establish three layers of the index system of sustainable 
island development: the overall layer (A), the system layer (B), and the index layer (C; Figure 2). The evaluation system of sustainable island development selected 27 indexes to completely express the level, the capability, behavior, reason, and the impetus of change of sustainable island development and attempted to conduct a quantitative evaluation of the sustainable development conditions for the comprehensive island. Furthermore, this evaluation system is also significative and instructive in some extent to provide a reference for the development evaluations of the nonresident islands.

2.2. The Weight of the Evaluation Index. The determination of weight is the crucial problem for the variety of evaluation and decision-making, and the rationality of the weight setting directly affects the accuracy of the evaluation results. Consequently, avoiding artificial randomness to the greatest extent and obtaining a rational weight setting are very important and difficult for multiobjective evaluation and decision-making.

2.2.1. Determination of Objective Weight. The entropy method [28] is a relatively objective weighting method. This method completely relies on the relations of the assessment indictor data and forms a judgment matrix to calculate the entropy to determine the weight of each index. Thus, the determination of the index weight is objective, and the specific calculation steps are as follows.

Entropy of the assessment index $i$ :

$$
H_{i}=-\frac{1}{\ln n} \sum_{j=1}^{n} f_{i j} \ln f_{i j},
$$

among which:

$$
\begin{gathered}
f_{i j}=\frac{1+b_{i j}}{\sum_{j=1}^{m}\left(1+b_{i j}\right)}, \\
i=1,2, \ldots, m ; j=1,2, \ldots, n ; 0 \leq H_{i}<1 .
\end{gathered}
$$
is

Consequently, the entropy weight of the assessment index

$$
w_{i}^{*}=\frac{1-H_{i}}{m-\sum_{i=1}^{n} H_{i}} .
$$

If $H_{i} \rightarrow 1(i=1,2, \ldots, m)$ of the index, the small changes of the entropy may lead to the changes in the weight of the indexes exponentially. Hence, it is very unreasonable. Referring to Zhou et al. [28], the following improvements of formula (3) were made:

$$
w_{i}^{* \prime}=\frac{\sum_{i=1}^{n} H_{i}+1-2 H_{i}}{\sum_{i=1}^{n}\left(\sum_{i=1}^{n} H_{i}+1-2 H_{i}\right)} .
$$

\subsubsection{Experience Weight by the Nonstructural Decision-} Making Fuzzy Model. While analyzing the AHP model, Professor Chen Shouyu [23] made a binary comparison of the properties of elements by comparing their importance. Subsequently, with certain defects, a nonstructural decisionmaking fuzzy theory model has been offered. The specific calculation steps are as follows.
Set the following target set which is about to compare the importance:

$$
P=\left\{p_{1}, p_{2}, \ldots, p_{m}\right\}
$$

$p_{i}$ is the target number $i$ of this target set, $i=1,2, \ldots, m$; $m$ is the total number of the target set. Conduct the binary comparison between $p_{k}$ and $p_{l}$. If

(1) $p_{k}$ is more important than $p_{l}$, the sort scale $e_{k l}=1$, and $e_{l k}=0$;

(2) $p_{k}$ and $p_{l}$ is of equal importance, $e_{k l}=0.5$, and also $e_{l k}=0.5$;

(3) $p_{l}$ is more important than $p_{k}$, then $e_{k l}=0$, and $e_{l k}=1$, $k=1,2, \ldots, m ; l=1,2, \ldots, m$.

And obtain the following binary comparison matrix of target set concerning the importance:

$$
\mathbf{E}=\left(\begin{array}{cccc}
e_{11} & e_{12} & \cdots & e_{1 m} \\
e_{21} & e_{22} & \cdots & e_{2 m} \\
\vdots & \vdots & & \vdots \\
e_{m 1} & e_{m 2} & \cdots & e_{m m}
\end{array}\right)=\left(e_{k l}\right)
$$

which meets

(1) the value of $e_{k l}$ can be set only from 0, 0.5, 1;

(2) $e_{k l}+e_{l k}=1$;

(3) $e_{k k}=e_{l l}=0.5, k=l$.

According to the descending sequence of the sum of each row in the binary comparison matrix, the order of importance of the target can be obtained under the circumstance of consistency.

Next, the targets are compared with each other in terms of the order of importance according to Table 1, and we get the binary comparison matrix

$$
\boldsymbol{\beta}=\left(\begin{array}{cccc}
\beta_{11} & \beta_{12} & \cdots & \beta_{1 m} \\
\beta_{21} & \beta_{22} & \cdots & \beta_{2 m} \\
\vdots & \vdots & & \vdots \\
\beta_{m 1} & \beta_{m 2} & \cdots & \beta_{m m}
\end{array}\right)=\left(\beta_{i j}\right)
$$

which meets

$$
\begin{gathered}
0 \leq \beta_{i j} \leq 1, \quad i \neq j, \\
\beta_{i j}+\beta_{j i}=1, \\
\beta_{i j}=0.5, \quad i=j .
\end{gathered}
$$

In this matrix, $\beta_{i j}$ is the fuzzy scale of the importance of the target $i$ for $j$, when the target $i$ compares with $j$ in terms of importance; $\beta_{j i}$ is the fuzzy scale of the importance of the target $j$ for $i$. Then, sum the fuzzy scale value $\beta_{s t}$ of each row 


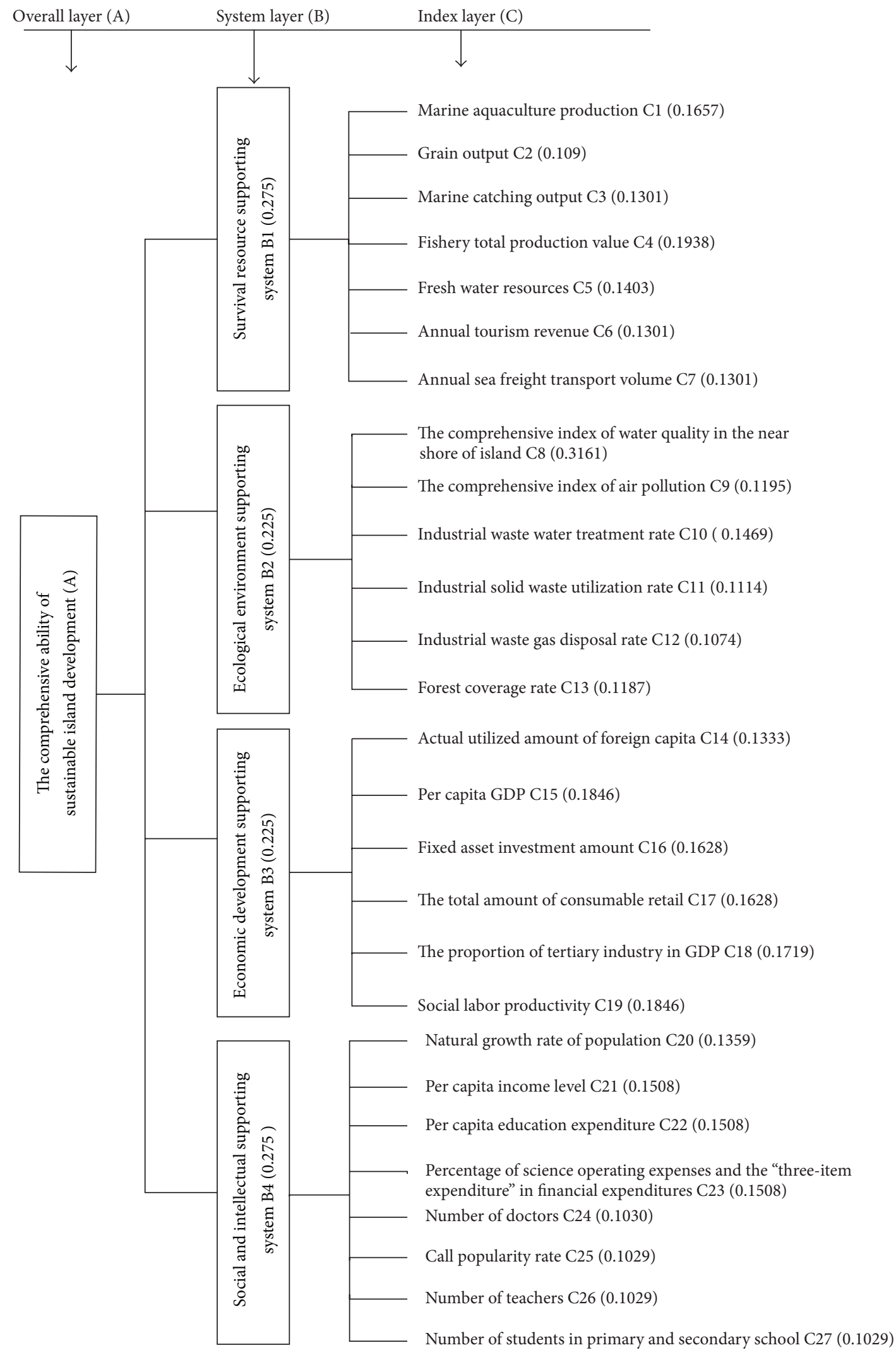

FIGURE 2: The evaluation index system of sustainable island development. 
TABLE 1: The table of the relationship between fuzzy tone factor and fuzzy scale.

\begin{tabular}{lc}
\hline Fuzzy tone factor & Fuzzy scale \\
\hline \multirow{2}{*}{ Equal } & 0.50 \\
& 0.525 \\
Slightly & 0.55 \\
Somewhat & 0.575 \\
& 0.60 \\
Rather & 0.625 \\
& 0.65 \\
Obviously & 0.675 \\
& 0.70 \\
Remarkably & 0.725 \\
Very & 0.75 \\
Extra & 0.775 \\
Exceedingly & 0.80 \\
Extremely & 0.825 \\
Incomparable & 0.85 \\
& 0.875 \\
& 0.90 \\
& 0.925 \\
& 0.95 \\
& 0.975 \\
& 1.0 \\
\hline
\end{tabular}

in the matrix $\boldsymbol{\beta}$, and further normalize to get the following weight vector of the target set:

$$
\begin{aligned}
& \mathbf{w}=\left(\begin{array}{llll}
w_{1} & w_{2} & \cdots & w_{m}
\end{array}\right)= \\
& \left(\frac{1}{\sum_{i=1}^{m}\left(1-\beta_{1 i}\right) / \beta_{1 i}} \quad \frac{\left(1-\beta_{12}\right) / \beta_{12}}{\sum_{i=1}^{m}\left(1-\beta_{1 i}\right) / \beta_{1 i}} \cdots\right. \\
& \left.\frac{\left(1-\beta_{1 m}\right) / \beta_{1 m}}{\sum_{i=1}^{m}\left(1-\beta_{1 i}\right) / \beta_{1 i}}\right) \text {. }
\end{aligned}
$$

2.2.3. Comprehensive Weight. The comprehensive weight of evaluation indexes is as follows:

$$
w_{i}=\frac{\left(w_{i}^{1} \cdot w_{i}^{2}\right)}{\sum_{i=1}^{m} w_{i}^{1} w_{i}^{2}}
$$

$W_{i 1}$ is the objective weight of $i$ index determined by entropy method. $w_{i 2}$ is the experience weight of $i$ index determined by the nonstructural decision-making fuzzy model.

2.3. Calculation of the Synthetic Index. The synthetic index of sustainable island development is got by weighted summing up of the index coefficients of sustainable island development at the base of the normalization of index data, and the formula is as follows:

$$
\begin{gathered}
I=\sum_{i=1}^{n}\left(W_{i} * U_{i}\right), \\
U_{i}=\sum_{j=1}^{n}\left(W_{j} * V_{i}\right) .
\end{gathered}
$$

$W_{i}$ is the weight of supporting systems of sustainable island development, $\sum_{i=1}^{n} W_{i}=1 ; U_{i}$ is the assessment index value of the supporting systems; $W_{j}$ is the weight of the assessment indexes of sustainable island development, $\sum_{j=1}^{n} W_{j}=1 ; V_{i}$ is the standardized value of the assessment indexes of sustainable island development. Considering the features and relevant studies $[14,18,20,29,30]$ of sustainable island development, the synthetic index of sustainable island development can be divided into 5 levels: $I \geq 0.8$ represents an excellent condition of sustainable development; $0.7 \leq I<$ 0.8 represents a good condition of sustainable development; $0.5 \leq I<0.7$ represents a moderate condition of sustainable development; $0.4 \leq I<0.5$ presents a weak condition of sustainable development; $I<0.4$ represents a very weak condition of sustainable development.

\section{Results and Discussion}

3.1. Overview of the Study Area. The relatively ideal condition for demonstrating the assessment of sustainable island development is to take a certain island as a research sample. However, considering the difficulties in acquiring island data and the significant role of the country island in the implementation of the management of the marine environment, marine resources, maritime rights, and interests, this paper selected counties with more comprehensive information as the basic statistic unit of sustainable island development, and Changhai County of China is selected as the sample of sustainable island development assessment.

Located in the northern Yellow Sea on the east of Liaodong Peninsula of Liaoning Province of China, Changhai County is the only county in northeast China with territory consisting of islands, and it is also the only island county in the Chinese boundary (Figure 3). Covering a total island area of 119 square kilometers and with a coastal line of 359 kilometers and a maritime space of 7,720 square kilometers, Changhai County is primarily engaged in fisheries, and it is also the most developed island area in Liaoning Province. Changhai County governs two towns of Dachangshan Island and Zhangzi Island, three townships of Xiaochangshan, Guanglu, and Haiyang, 23 administrative villages, and 7 communities, with its county government located in the town of Dachangshan Island. By the end of 2008, the county had 26,232 registered households with a population of 74,010 among which 41,771 people lived in towns and townships.

Changhai County of China is a typical example of Chinese island development, displaying the striking features of island development in terms of strategic value, economic and resource values, ecological and environmental values, as well as social and cultural values. However, due to its incomplete 


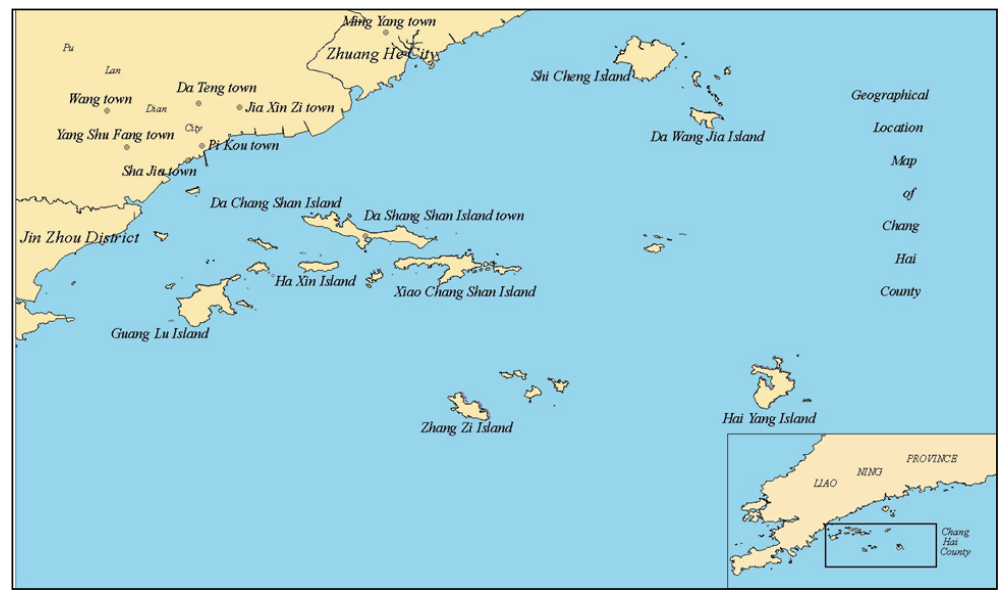

FIGURE 3: Geographical location map of Changhai County of China.

infrastructure, with the economic development of the island, the resources of Changhai County are consumed rapidly, and the contradictions among economic system, environmental system, and ecological system become increasingly sharp during the process of economic development, which has restricted the development of Changhai and made the economic development of Changhai County rank in a relatively backward position among the 12 island counties of China. Therefore, it is of particular importance to research the sustainable development system of Changhai.

3.2. Sources of Data. The index data are primarily from statistical yearbooks of Changhai County (2001-2008), the environmental quality reports of Changhai County (2001-2005), the annual environmental monitoring reports of Changhai County (2006-2007), the statistical annuls of the economy, and the social development of Changhai County (2001-2008). A majority of the index data can be obtained directly from the statistical annuals, and a minority of the data was acquired through calculation.

3.3. The Calculation of Index Weight and the Synthetic Index. The following paragraph explains the detailed process of determining the synthetic index by assigning the following 6 index weights: the comprehensive index of seawater quality index of island environmental supporting system layer $\left(C_{8}\right)$, the comprehensive index of air pollution $\left(C_{9}\right)$, industrial waste water treatment rate $\left(C_{10}\right)$, industrial solid waste utilization rate $\left(C_{11}\right)$, industrial waste gas disposal rate $\left(C_{12}\right)$, and forest coverage rate $\left(C_{13}\right)$.

We determined and standardized the index statistical data matrix of Changhai County from 2001 to 2007. The standardized matrix is as follows:

$$
B=\left[\begin{array}{cccccc}
1 & 0.4043 & \cdots & \cdots & 1 & 1 \\
0 & 1 & \cdots & \cdots & 0.3765 & 0 \\
0.9229 & 0.0284 & \cdots & \cdots & 0.8580 & 0.9589 \\
\cdots & \cdots & \cdots & \cdots & \cdots & \cdots \\
\cdots & \cdots & \cdots & \cdots & \cdots & \cdots \\
0.0898 & 0.6454 & \cdots & \cdots & 0.1488 & 0.7352
\end{array}\right] .
$$

Following the entropy weight solution procedure, we can obtain the 6 index weights

$$
w_{1}^{\prime}=(0.7078,0.5182,0.4901,0.3717,0.3583,0.3339) .
$$

Normalizing the entropy weight of the index, we get the objective weight of the indexes

$$
w_{1}=(0.2546,0.1864,0.1763,0.1337,0.1289,0.1201) .
$$

According to the theorem of the order of importance, the following matrix $E$, the scale of the order of importance of the six indexes, can be obtained:

$$
E=\left[\begin{array}{cccccc|c}
0.5 & 1 & 1 & 1 & 1 & 1 \\
0 & 1 & 0.5 & 1 & 1 & 1 & (1 \\
0 & 0.5 & 0 & 1 & 1 & 1 & (3) \\
0 & 0 & 0 & 0 & 0.5 & 0 & (2) \\
0 & 0 & 0 & 1 & 1 & 0.5 & (5) \\
0 & 0 & 0 & 0.5 & 1 & 0
\end{array}\right] \text { (4) }
$$

According to the order of importance matrix $E$, based on the consideration of expert opinions and references to numerous studies in the literature, we conclude that $C_{8}$ is slightly more important than $C_{9}$, is obviously more important than $C_{10}, C_{11}$, and $C_{12}$, and is slightly more important than $C_{13}$; Compared with $C_{10}, C_{11}$, and $C_{12}, C_{9}$ is in between slightly more important and relatively more important and is equally important with $C_{13} ; C_{10}$ is equally important with $C_{11}$ and $C_{12}$; compared with $C_{10}, C_{13}$ is between slightly more important and relatively more important. According to the corresponding relation between fuzzy tone factors and fuzzy scale values in Table 1, a two-dimensional comparison matrix $\beta$ with 6 targets can be determined as follows:

$$
\beta=\left[\begin{array}{cccccc}
0.5 & 0.6 & 0.7 & 0.7 & 0.7 & 0.6 \\
0.4 & 0.5 & 0.625 & 0.625 & 0.625 & 0.5 \\
0.3 & 0.375 & 0.5 & 0.5 & 0.5 & 0.375 \\
0.3 & 0.375 & 0.5 & 0.5 & 0.5 & 0.375 \\
0.3 & 0.375 & 0.5 & 0.5 & 0.5 & 0.375 \\
0.4 & 0.5 & 0.625 & 0.625 & 0.625 & 0.5
\end{array}\right] .
$$




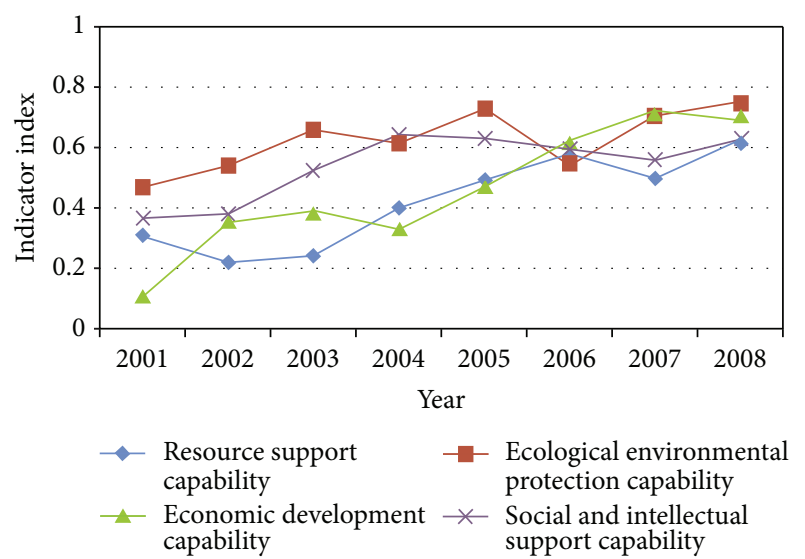

FIgURE 4: The comprehensive index of supporting systems.

The sum of the fuzzy scale values can be used to show the weight vector of the index, as follows:

$$
\begin{aligned}
w & =\left(\sum_{t=1}^{m} \beta_{1 t}, \sum_{t=1}^{m} \beta_{2 t}, \ldots, \sum_{t=1}^{m} \beta_{m t}\right) \\
& =(3.8,3.275,2.55,2.55,2.55,3.025) .
\end{aligned}
$$

Normalizing the fuzzy scale values matrix, we obtain the weights of 6 indexes of the island resources support system:

$$
w_{2}=(0.2141,0.1845,0.1437,1437,0.1437,0.1704) \text {. }
$$

According to formula (10), we can combine the forementioned mathematical weights with the experience weight by the nonstructural decision-making fuzzy model and eventually obtain the comprehensive weights of 6 indexes:

$$
w=(0.3161,0.1995,0.1469,0.1114,0.1074,0.1187) .
$$

Because the calculation method of the weights of other layers is the same as this, this paper omitted the details and directly showed the weight results of sustainable island development support system, which is shown in Figure 2.

The synthetic evaluation indexes of the sustainable development systems of Changhai County are shown in Figure 4, Figure 5, and Table 2.

3.4. The Analysis of Results. During the period from 2001 to 2008, the comprehensive sustainable development capability of Changhai County improved continuously and steadily, with its value $(A)$ increasing to 0.67 in 2008 from 0.31 in 2001, which indicates that the comprehensive strength of sustainable development had doubled. By 2008, the comprehensive sustainable development capability of Changhai County had reached the middle development level (0.67), and Changhai County had achieved significant development in economic, social, scientific, and educational levels.

In the evaluation system of sustainable development of Changhai County, the ecological environmental protection system is of the highest realization degree in sustainable development, whereas the survival resource system and the

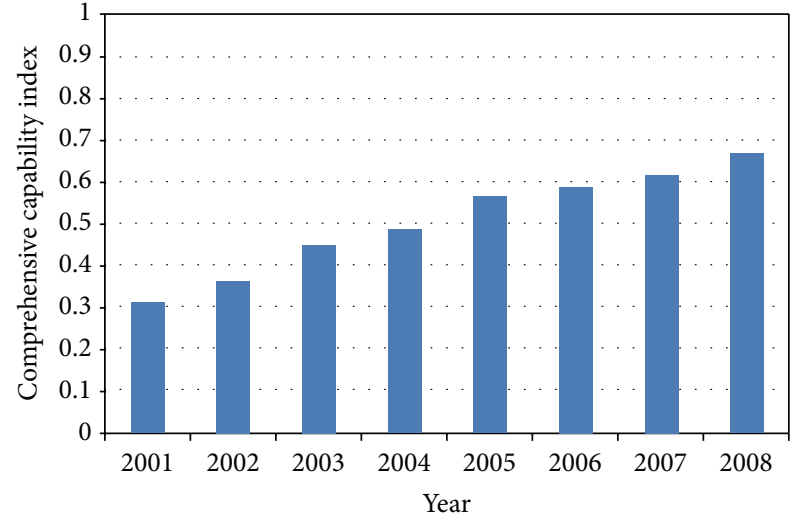

FIgURE 5: The comprehensive capability index of sustainable development (2001-2008).

social and intellectual support system are of a relatively low realization degree. The low sustainable development capability of the survival resource system and the social intellectual support system is the primary reason why the comprehensive sustainable development level of Changhai County is in the middle, which limits the improvement of the comprehensive sustainable development capability.

The survival resource support ability of Changhai County is at a weaker level of sustainable development during the period from 2001 to 2008, with the trend of slow rising. Within the period, all indexes of the survival resource support system are at lower levels, except for per capita amount of aquatic products. Although per capita water supply capacity, which is among these indexes, becomes stronger and stronger, the maximum amount of per capita water supply capacity is 33.8 cubic meters per person, which owns only $25 \%$ of the national average and $73.4 \%$ lower than the average level of Liaoning Province. The power supply capacity of Changhai County is strengthening, and the capacity in 2011 (1497.1 kwh per person) grows three times as much as that of 2001, strengthening the power resource supply ability of sustainable development of Changhai County. However, the base number of per capita power supply capacity is low, only owning $32 \%$ of the average of Dalian (in Dalian, the amount of per capita power supply is $4685.8 \mathrm{kwh}$ per person). Within the period, the area of per capita marine area lasts between $9.5 \mathrm{hm}^{2}$ and $10.5 \mathrm{hm}^{2}$, which are among the intermediate and advanced levels. This indicates that marine areas, coastlines, beaches, and other resources are well protected, and the utilization of marine area is quite efficient, which ensures the sustainable development of Changhai County marine islands. The yield of agricultural products in Changhai is quite low, with the per capita yield only $102.55 \mathrm{~kg}$ at most and $75 \%$ lower than the average level of China and Liaoning Province. The grain supply mainly depends on mainland, but the grain sources and marine transport are restricted by many circumstances. Thus, the gross supply capacity of Changhai County is very vulnerable. The fishery of Changhai County is one of the competitive industries all the time, which has been proved that during the period, the per capita aquatic product 
TABLE 2: The synthetic evaluation indexes of sustainable development systems of Changhai county.

\begin{tabular}{lccccccccc}
\hline & 2001 & 2002 & 2003 & 2004 & 2005 & 2006 & 2007 & 2008 \\
\hline Resource support capability & 0.31 & 0.22 & 0.24 & 0.40 & 0.49 & 0.58 & 0.50 & 0.62 \\
Ecological environmental protection capability & 0.47 & 0.54 & 0.66 & 0.62 & 0.73 & 0.55 & 0.71 & 0.75 \\
$\begin{array}{l}\text { Economic development capability } \\
\text { Social and intellectual support capability }\end{array}$ & 0.11 & 0.35 & 0.39 & 0.33 & 0.47 & 0.62 & 0.72 & 0.70 \\
$\begin{array}{l}\text { Comprehensive capability of sustainable } \\
\text { development }\end{array}$ & 0.37 & 0.38 & 0.53 & 0.65 & 0.63 & 0.59 & 0.56 & 0.63 \\
\hline
\end{tabular}

yield is rising, and the yield in 2011 is 2.3 times as much as that in 2001, which ranks the second in the list of China's 12 island counties. The fishery development of Changhai County has been in the forefront of the nation, which promotes the sustainable development of Changhai County to some extent. The cargo throughput of the ports of Changhai County is at low level, and the maximum amount of marine transport in 2011 is 1.79 million tons, which ranks the tenth in the list of China's 12 island counties. That is to say, the port resources are not thoroughly utilized. In conclusion, although many of the indexes of survival resource support ability of Changhai County are rising, the maximum value of each index remains at the low level, showing that the resource support capacity of sustainable development is quite poor.

The ecological environmental support capacity of Changhai County is at a stronger level during the period from 2001 to 2008. During the period, the average for many years of seawater water quality comprehensive index of inshore region of Changhai County is 2.09, and that of drinking water in land is 1.41. In this case, the quality of both marine water and drinking water has reached higher criterion. The per capita public grassland area of Changhai County is rising from 7 square meters per person in 2001 to 10.43 square meters per person in 2011 by $49 \%$. This indicates that Changhai County is paying more and more attention to ecological environment. Marine disaster has become the main natural disaster, which brings about that the loss disasters can directly affect the level of sustainable development. The proportion of the loss of marine disasters in GDP goes up, and such proportion in 2011 is $16.6 \%$. This indicates that Changhai County is weak in handling marine disasters. In conclusion, although the ecological environmental support ability of Changhai County is generally at a higher level, it is quite poor for Changhai County in overcoming natural disasters. Therefore, it is highly suggested that the government should improve the marine disaster forecast and prevention.

Among 4 support systems of sustainable development of Changhai County, the economic development support system has the most rapid growth. The sustainable development index reached 0.70 in 2008, indicating the middle sustainable development level. The success of the economic development support system is closely related to the development strategy of constructing the "Liaoning at Sea" and "Dalian at Sea" demonstration area projects and to prosperous fisheries, industries, and tourism, which have been implemented by Changhai County in recent years. Social labor productivity, investment in fixed assets, and total sales of consumer goods have increased greatly. In 2008, Changhai County realized a gross regional product (GRP, large-caliber) of 3,463.46 million Yuan, and GRP per capita reached 46,729 Yuan (Statistical Bureau of Changhai County in China (2001-2008)), which indicates that Changhai County ranked among the top national counties for marine economy. However, similar to most island counties, a natural traffic obstacle exists between Changhai County and the outside due to its unique geographic location and resource features. The traffic construction between islands and between land and the islands is slow, and meteorological conditions greatly influence the flow of people and logistics, having become one of the important factors limiting the economic development of Changhai County. Furthermore, the economic structure of Changhai County is singular, with the primary industry focusing on fishery. In 2008, the proportion of the three industries (primary industry, secondary industry, and tertiary industry) in Changhai County was $74.2: 13.9: 11.9$, and the contribution rate of the primary industry to economic growth reached $90 \%$. So, Changhai County needs to change the existing fishery-focused economic development mode, accelerate the economic restructuring, and promote the overall optimization and upgrading of three industries.

Among 4 support systems of the sustainable development of Changhai County, the social and intellectual support system shows the slowest growth. As observed from the internal realization indexes of sustainable development, the proportion of educational expenditure per capita, expenditure on science and three items of expenditure on science and technology in financial expenditure, as well as the number of teachers, the number of enrolled students in primary and middle schools, and other intellectual support factors greatly influence the realization of sustainable development of the social and intellectual support system. During the period from 2001 to 2008, the income per capita of Changhai increased continuously and steadily, increasing to 17,256 Yuan in 2008 from 5,399 Yuan in 2001, an increase of $219 \%$. However, the increase in the investment in educational funds per capita was not high. From 2001 to 2007, the investments in educational funds per capita were 336 Yuan, 340 Yuan, 390 Yuan, 430 Yuan, 617 Yuan, 517 Yuan, and 693 Yuan, respectively; the proportion of expenditure on science and three items of expenditure on science and technology in financial expenditure was approximately 1\% (Statistical Bureau of Changhai County in China (2001-2008)). The insufficient 
investment in education and scientific research and "having difficulty in attracting and retaining talents" are still problems restricting the development of Changhai County. Consequently, it is necessary for Changhai County to provide flexible employment mechanisms, establish a sound talent training system, increase investment in education and scientific research, and stabilize a talent team to enhance sustainable development.

\section{Conclusion}

Islands are an important part of Chinese territory and are also important bases for ocean development. The sustainable island development relates to the sustainable development of the ocean and even the national economic system [31]. This paper (1) selected indexes in terms of survival resource support, ecological environmental support, economic development support, and social and intellectual support, (2) established the evaluation index system and evaluation model of sustainable island development, (3) analyzed and evaluated the sustainable island development level, development orientation, and restrictive factors, (4) combined the entropy method with the nonstructural decision-making fuzzy set theory model to determine the weight of the evaluation indexes of sustainable island development, (5) took Changhai County of China as an evaluation example of sustainable island development, and (6) conducted quantitative research on the sustainable development conditions of the county. The results showed that the comprehensive sustainable development capability of Changhai County improved continuously. The sustainable development index increased to 0.67 in 2008 from 0.31 in 2001, reaching the middle development level. Among the support systems for the sustainable development of Changhai County, the ecological environmental system has been most fully realized in sustainable development, whereas the survival resource system and the social and intellectual support system are of a relatively low realization degree. The primary reason why the sustainable development of Changhai County is in the middle level is that the county has relatively few survival resources per capita, poor survival sustainability, a relatively low educational level, and low technological and management capability, which limit the improvement of the comprehensive sustainable development capability. The survival sustainability level and island environmental and protection level are important factors in determining the sustainable development capability, whereas fresh water resources, mariculture, the extent of tertiary industry development, educational investment, and the state of scientific research are restrictive factors influencing sustainable development. Therefore, Changhai County should properly enhance the infrastructure construction and increase the investment in education and scientific research to promote the improvement of the comprehensive sustainable development capability. Furthermore, in the process of island development and construction, Changhai County should enhance the protection of the resources and the environment, reasonably develop and utilize island resources, and truly promote the construction and development of the island.

\section{Acknowledgment}

Foundation item: under the auspices of 908 special fund of the State Oceanic Administration: the offshore marine environment quality evaluation of Liaoning province (LN908-02-04).

\section{References}

[1] L. Sun, J. Ni, and A. G. Borthwick, "Rapid assessment of sustainability in Mainland China," Journal of Environmental Management, vol. 91, no. 4, pp. 1021-1031, 2010.

[2] J. Li and G. C. Wang, "Establishment and discussion of appraisement indicators system of islands stainable development," Marine Environmental Science, vol. 23, no. 1, pp. 54-57, 2004 (Chinese).

[3] I. Moffatt, "Ecological footprints and sustainable development," Ecological Economics, vol. 32, no. 3, pp. 359-362, 2000.

[4] B. Du, K. Zhang, G. Song, and Z. Wen, "Methodology for an urban ecological footprint to evaluate sustainable development in China," International Journal of Sustainable Development and World Ecology, vol. 13, no. 4, pp. 245-254, 2006.

[5] C. Yang and J. P. H. Poon, "A regional analysis of China's green GDP," Eurasian Geography and Economics, vol. 50, no. 5, pp. 547-563, 2009.

[6] Q. Di, Z. Han, G. Liu, and H. Chang, "Carrying capacity of marine region in Liaoning Province," Chinese Geographical Science, vol. 17, no. 3, pp. 229-235, 2007.

[7] D. J. Chen, P. Li, J. Du, L. Liu, and X. Xu, “The evaluation of sustainable development based on ecological footprint and human development index-a case of marine fishery resources utilization in china," Science and Society, no. 5, pp. 96-103, 2006 (Chinese).

[8] J. W. Rogers, "Sustainable development patterns: the Chesapeake Bay region," Water Science and Technology, vol. 26, no. 12, pp. 2711-2721, 1992.

[9] M. D. Griffith and J. Ashe, "Sustainable development of coastal and marine areas in small island developing states: a basis for integrated coastal management," Ocean and Coastal Management, vol. 21, no. 1-3, pp. 269-284, 1993.

[10] M. D. Griffith, "Reflections on the implementation of the programme of action on the sustainable development of small island developing states (SIDS)," Ocean and Coastal Management, vol. 29, no. 1-3, pp. 139-163, 1995.

[11] K. C. Tran, "Public perception of development issues: public awareness can contribute to sustainable development of a small island," Ocean and Coastal Management, vol. 49, no. 5-6, pp. 367-383, 2006.

[12] T. B. Ramos, S. Caeiro, C. H. Douglas, and C. Ochieng, "Environmental and sustainability impact assessment in small islands: the case of Azores and Madeira," International Journal of Environmental Technology and Management, vol. 10, no. 2, pp. 223-240, 2009.

[13] J. Forster, I. R. Lake, A. R. Watkinson, and J. A. Gill, "Marine biodiversity in the Caribbean UK overseas territories: perceived threats and constraints to environmental management," Marine Policy, vol. 35, no. 5, pp. 647-657, 2011.

[14] X. Ni, Y. Q. Wu, J. Wu, J. Lu, and P. C. Wilson, "Scenario analysis for sustainable development of Chongming Island: water resources sustainability," Science of the Total Environment, vol. 439, no. 15, pp. 129-135, 2012. 
[15] S. Avdimiotis, "Necessity of the early warnings system for the development of new sustainable forms of tourism. The case of Chios island, North Aegean," Journal of Environmental Protection and Ecology, vol. 9, no. 2, pp. 431-435, 2008.

[16] M. Fortuny, R. Soler, C. Cánovas, and A. Sánchez, “Technical approach for a sustainable tourism development. Case study in the Balearic Islands," Journal of Cleaner Production, vol. 16, no. 7, pp. 860-869, 2008.

[17] R. Ciegis, J. Ramanauskiene, and B. Martinkus, “The concept of sustainable development and its use for sustainability scenarios," Engineering Economics, vol. 2, no. 62, pp. 28-37, 2009.

[18] B. Melnikas, "Sustainable development and creation of the knowledge economy: the new theoretical approach," Technological and Economic Development of Economy, vol. 16, no. 3, pp. 516-540, 2010.

[19] A. Barrera-Roldán and A. Saldívar-Valdés, "Proposal and application of a sustainable development index," Ecological Indicators, vol. 2, no. 3, pp. 251-256, 2002.

[20] M. Golusin and O. Munitlak Ivanović, "Definition, characteristics and state of the indicators of sustainable development in countries of Southeastern Europe," Agriculture, Ecosystems and Environment, vol. 130, no. 1-2, pp. 67-74, 2009.

[21] D. Karahasanovic, A. Avdic, and M. Cinjarevic, "Improving of sustainable development indicator with special focus on transition countries," Technics Technologies Education Management, vol. 5, no. 4, pp. 760-772, 2010.

[22] A. Vallega, "The role of culture in island sustainable development," Ocean and Coastal Management, vol. 50, no. 5-6, pp. 279300, 2007.

[23] S. Y. Chen, The Variable Fuzzy Sets Theory Model and Its Application, Dalian University of Technology Press, Dalian, China, 2009.

[24] S. Y. Chen and J. M. Hu, "Variable fuzzy assessment method and its application in assessing water resources carrying capacity," Journal of Hydraulic Engineering, vol. 37, no. 3, pp. 264-277, 2006 (Chinese).

[25] M. Gai and L. Zhou, "A study of the coordinated development of marine resources environment and economy of Liaoning Province using a variable fuzzy recognition model," Resources Science, vol. 33, no. 2, pp. 356-363, 2011 (Chinese).

[26] A. van Zeijl-Rozema, R. Cörvers, R. Kemp, and P. Martens, "Governance for sustainable development: a framework," Sustainable Development, vol. 6, no. 16, pp. 410-421, 2008.

[27] W. Y. Niu and Y. X. Lu, Overview of China's Sustainable Development, Science Press, Beijing, China, 2007.

[28] H. C. Zhou, G. H. Zhang, and G. L. Wang, "Multi-objective decision making approach based on entropy weights for reservoir flood control operation," Journal of Hydraulic Engineering, vol. 38, no. 1, pp. 100-106, 2007 (Chinese).

[29] D. F. Ye, "Relativity and sustainable development," Chinese Geographical Science, vol. 14, no. 1, pp. 75-81, 2004.

[30] W. X. Luan and N. Shen, "The research on social economic support system of sustainable development in changshan," Archipelagos Pacific Journal, vol. 10, pp. 65-75, 2005 (Chinese).

[31] Z. Tu, S. L. Yang, D. Hu, and D. Zhao, "Evaluation method of sustainable development capability of marine economy and application in Fujian Province," Marine Environmental Science, vol. 30, no. 6, pp. 819-822, 2011 (Chinese). 


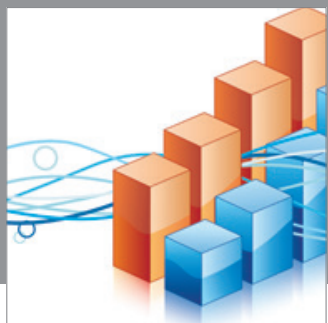

Advances in

Operations Research

mansans

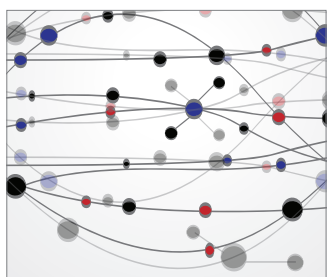

The Scientific World Journal
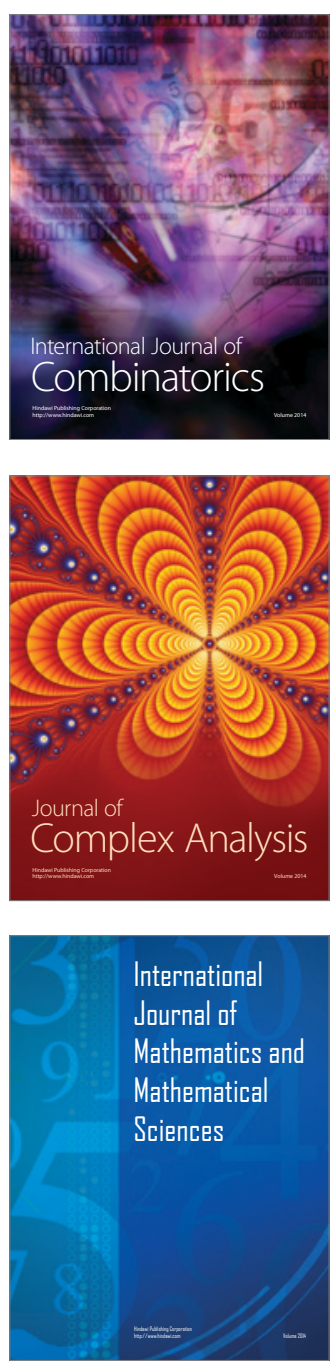
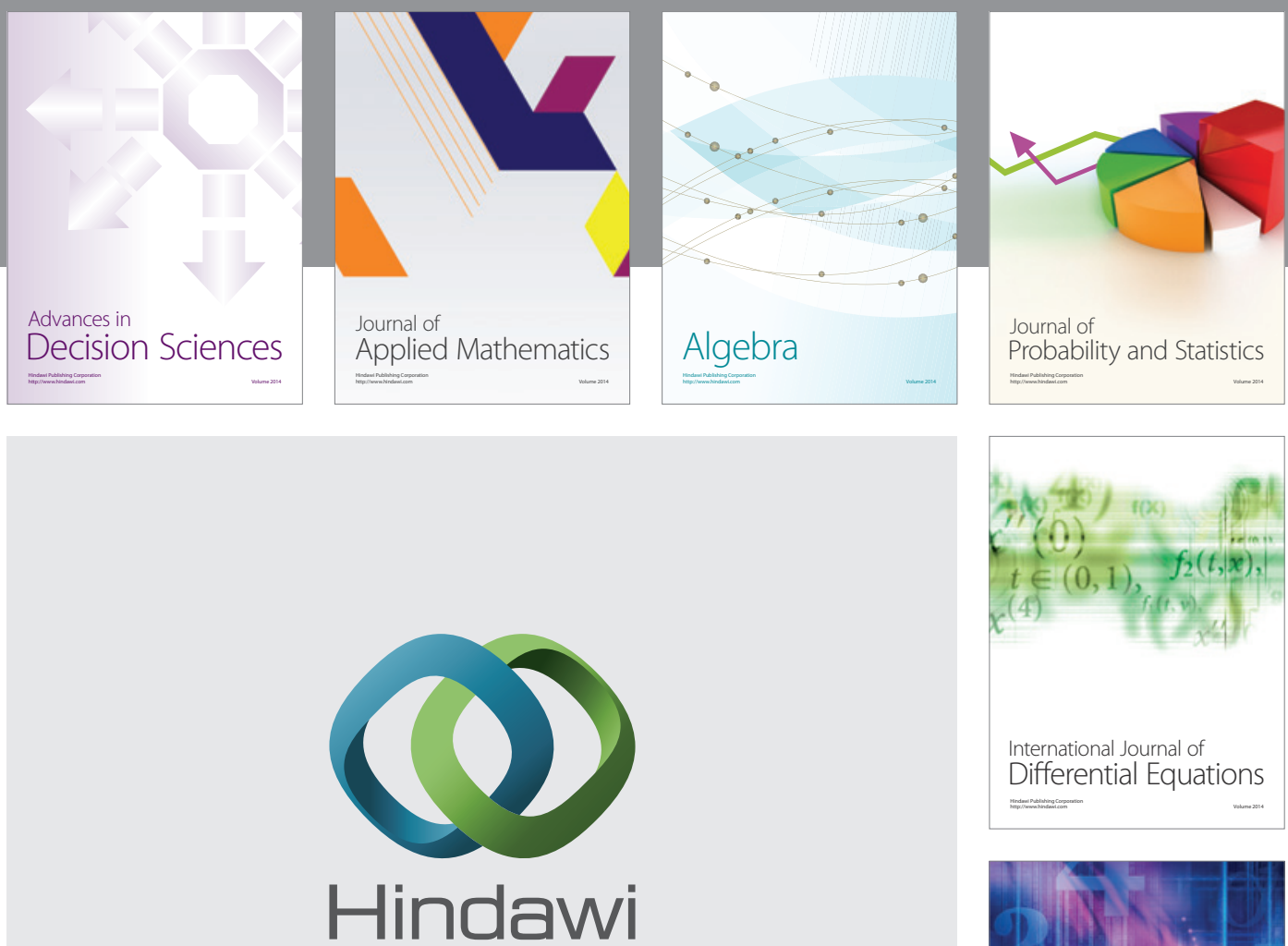

Submit your manuscripts at http://www.hindawi.com
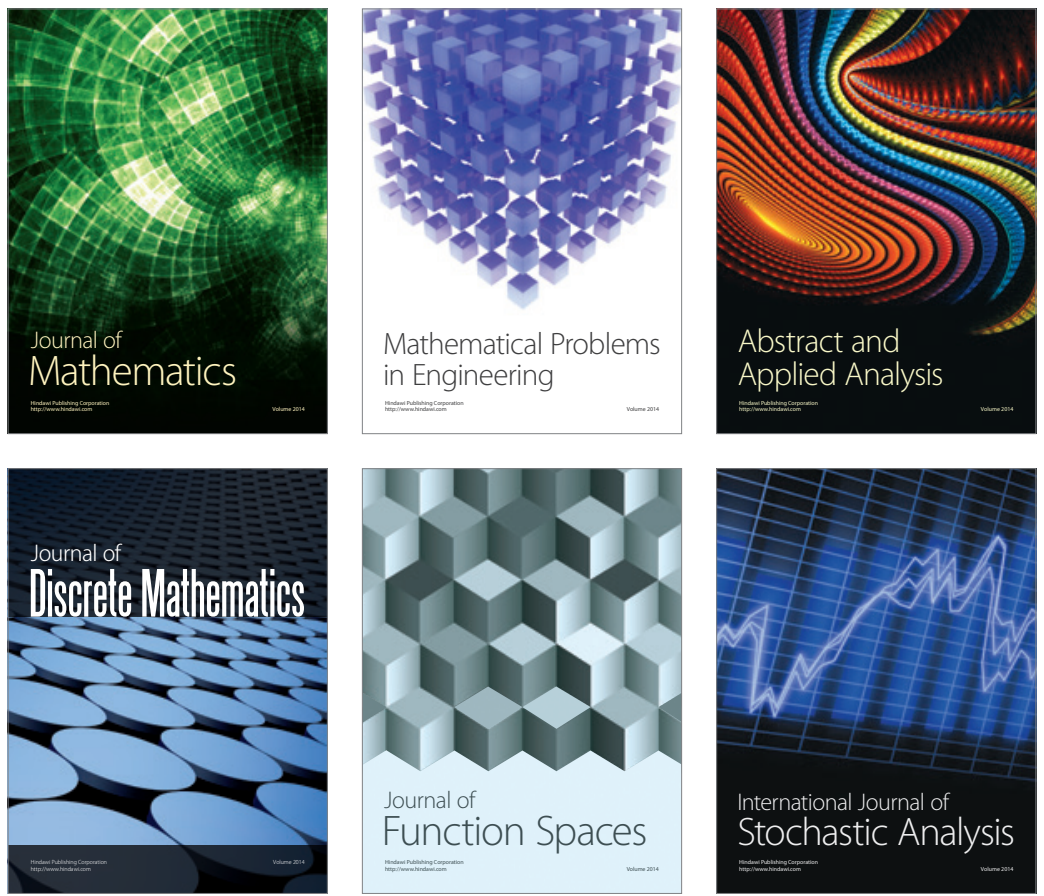

Journal of

Function Spaces

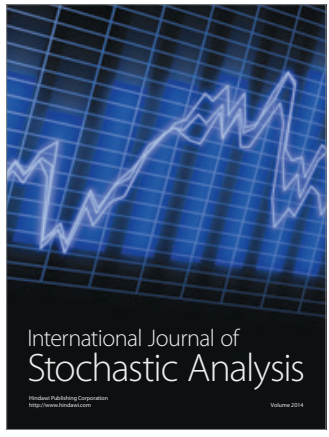

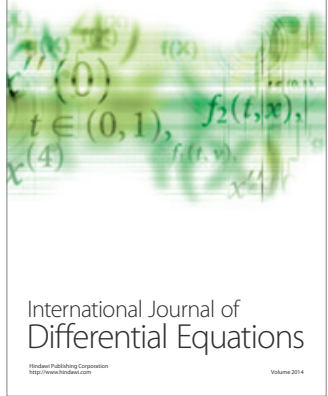
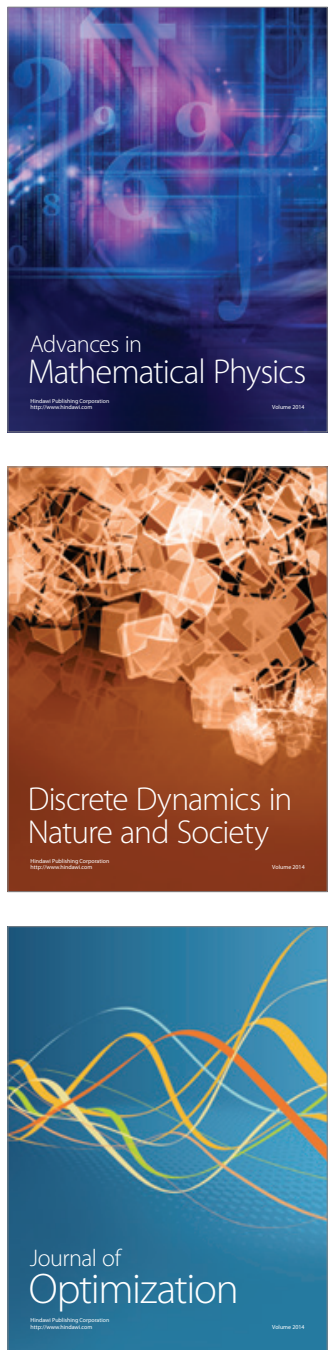